Have 15-year-olds become "greener" over the years?

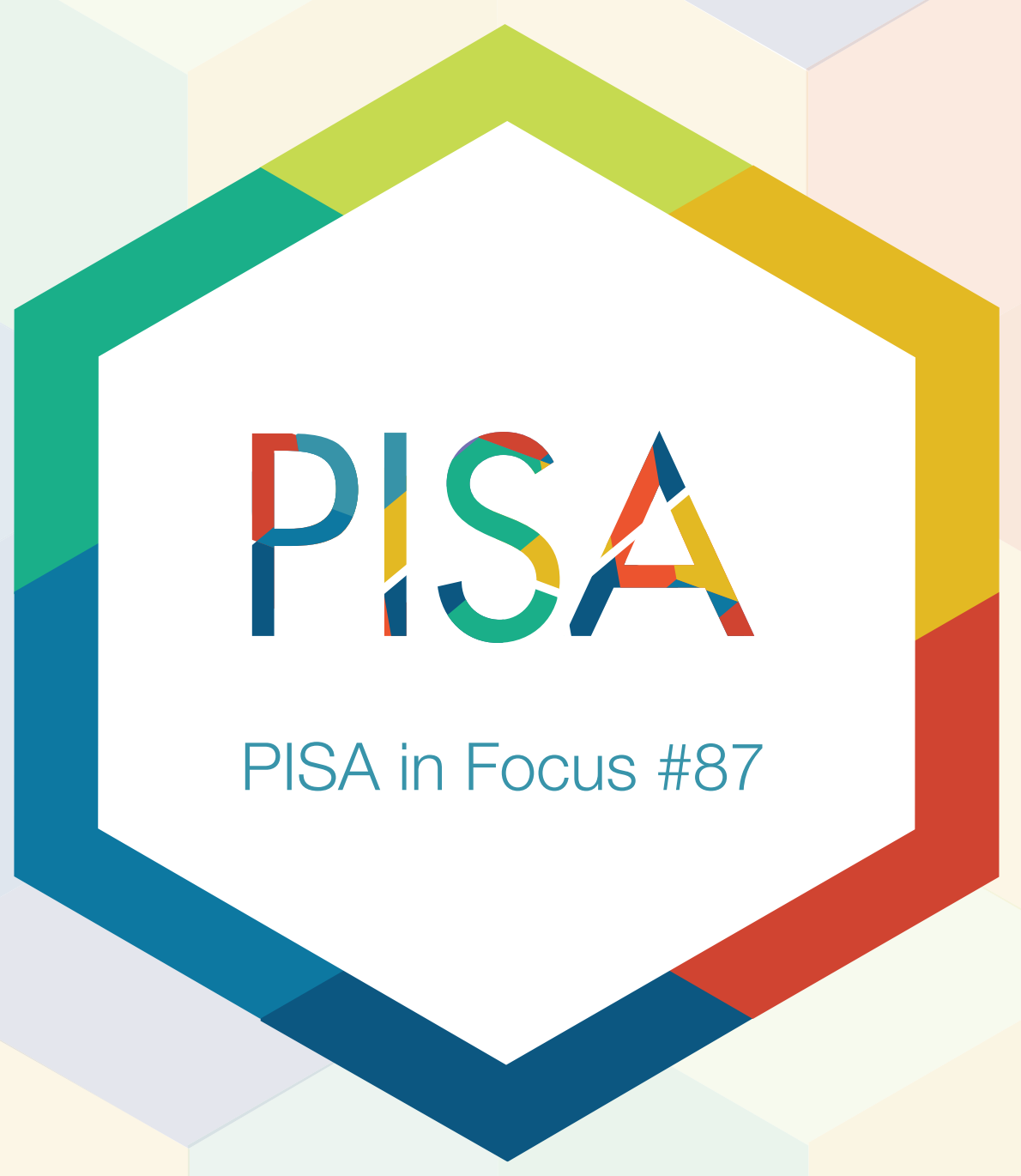




\section{Have 15-year-olds become "greener" over the years?}

- In the nine years from 2006 to 2015, the share of students who reported that they are informed or well-informed about environmental problems increased moderately, on average across OECD countries. At the same time, students did not become more optimistic about resolving these problems.

- Environmentally aware students are more pessimistic about the future of Earth. For instance, 15-year-old students who claimed to be informed about the increase of greenhouse gases were $43 \%$ more likely to consider that this problem would get worse over the next 20 years.

- Few characteristics of students and schools are positively associated with both environmental awareness and optimism about the environment, but the most important are the number of science activities in which students participate and students' exposure to enquiry-based teaching.

Many (bad) things have happened to our planet since PISA asked students about the environment more than a decade ago. The global temperature increased, glaciers continued to melt, coral reefs became increasingly endangered, sea levels rose about 3 centimeters, garbage continued piling up in oceans and man-made disasters, such as the Deepwater Horizon oil spill and the Fukushima nuclear disaster, have added more strains on our fragile planet's health. Through national and international initiatives, such as the Paris Climate Conference and agreement - also known as COP21 - governments are trying to co-ordinate efforts to protect the environment; but until society is fully aware of the consequences of inaction, the cost of action may appear too high. So, are students increasingly aware of environmental problems? Have 15-year-olds became more optimistic about the future of Earth? And who are the environmentally aware students?

\section{Environmental awareness and optimism OECD average}

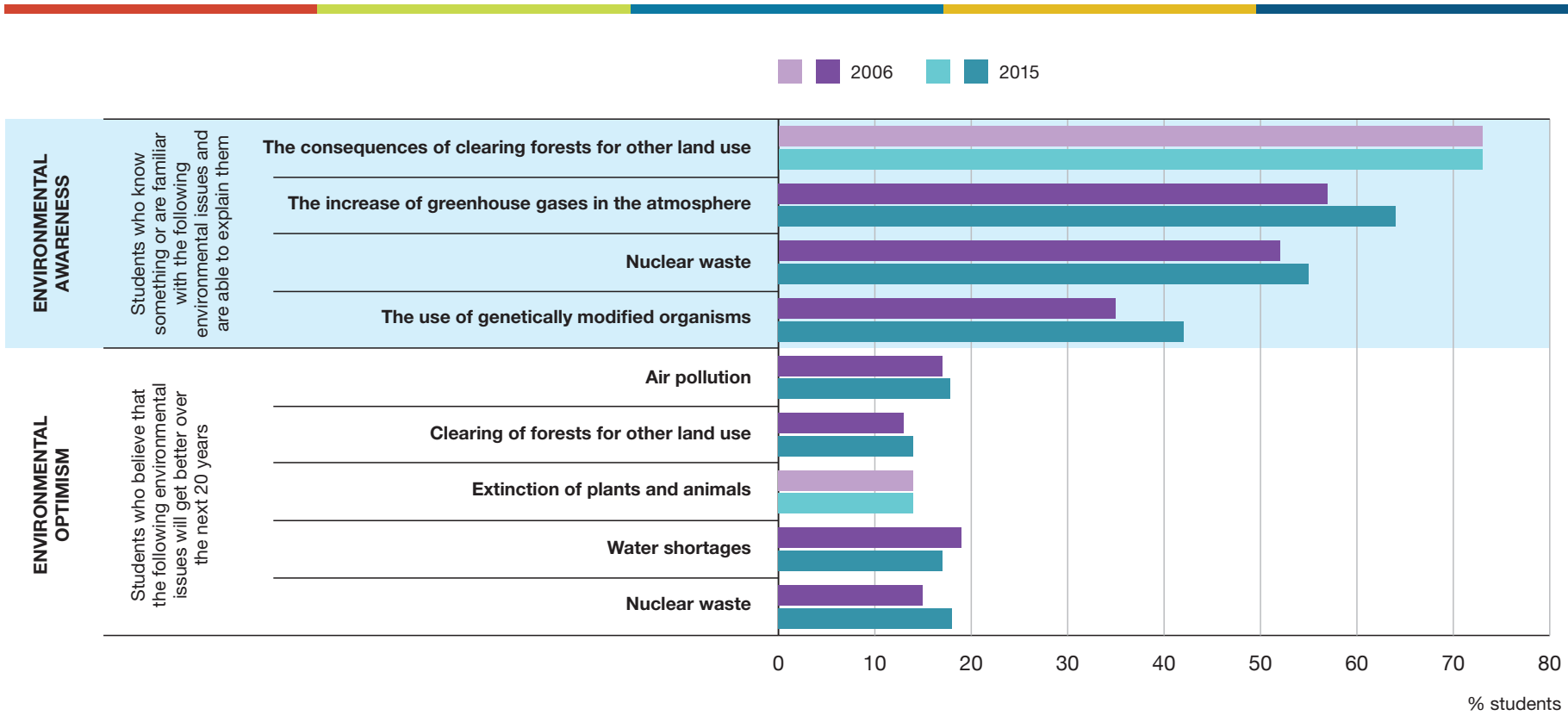

Notes: Lithuania acceded to the OECD on 5 July 2018. The OECD average does not include Lithuania.

Statistically significant differences between 2006 and 2015 are shown in darker tones.

Source: OECD, PISA Database. 


\section{Change between 2006 and 2015 in the...}

Index of environmental awareness

$\diamond$ Index of environmental optimism

Index dif.

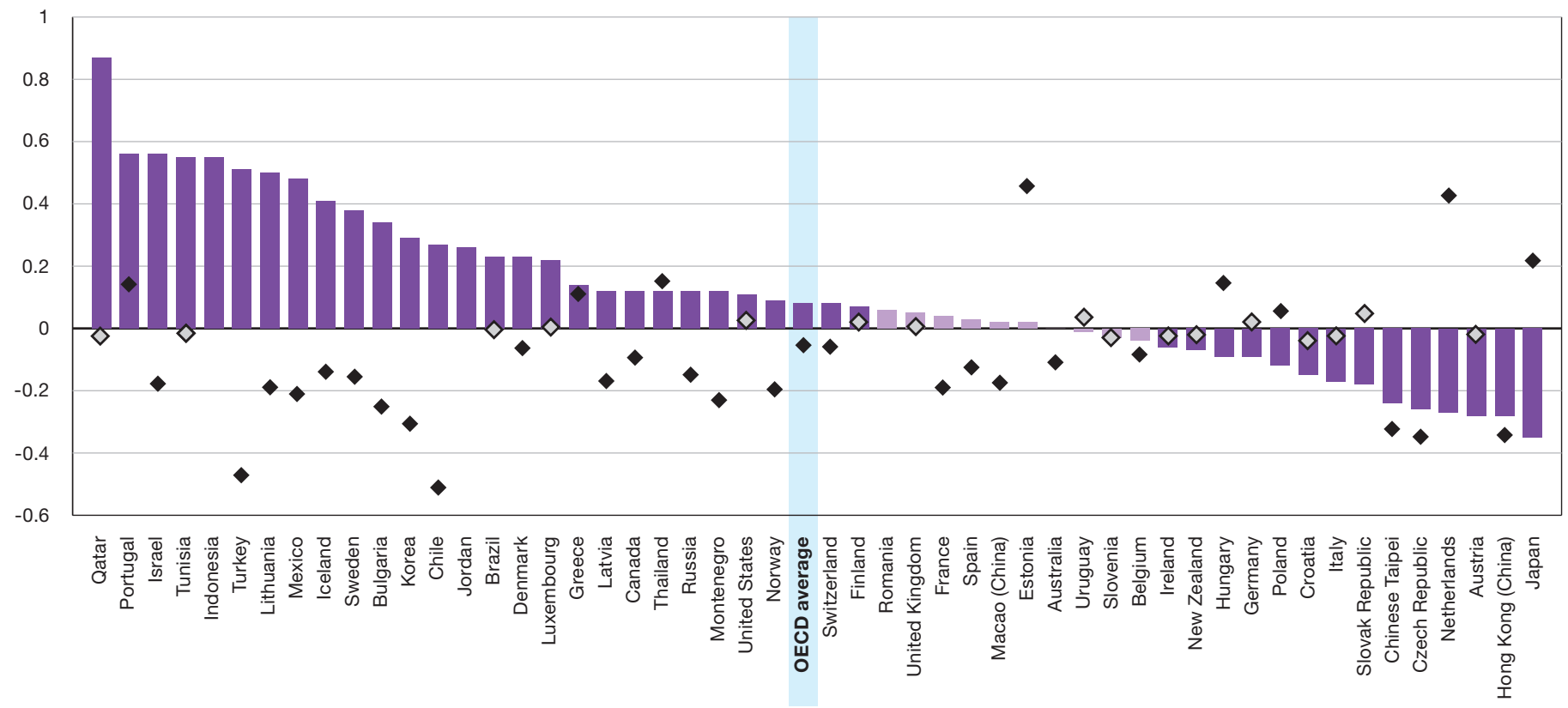

Notes: Statistically significant changes between 2006 and 2015 are shown in darker tones.

Lithuania acceded to the OECD on 5 July 2018. The OECD average does not include Lithuania

The indices of environmental awareness and optimism measure the extent to which students are knowledgeable and optimistic about environmental issues.

They have been scaled using Item Response Theory and have an average of zero and a standard deviation of one across OECD countries.

Source: OECD, PISA Database.

\section{Envirommental awareness is increasing among 15-year-olds.}

PISA asked 15-year-old students how informed they are about a number of environmental issues, such as air pollution, water shortages or nuclear waste. In the nine years from 2006 to 2015, and for most of the environmental issues cited in both cycles of PISA, the share of students who reported that they are informed ("I know something about this and could explain the general issue") or well-informed ("I am familiar with this and I would be able to explain this well") increased moderately, on average across OECD countries. For instance, the percentage of students who stated that they are informed about the increase of greenhouse gases in the atmosphere rose from $57 \%$ in 2006 to $64 \%$ in 2015, and a similar percentage-point increase was observed when students were asked about the use of genetically modified organisms.

This overall improvement in environmental awareness was largely the result of increases in Israel, Mexico, Portugal and Turkey in the extent to which students reported being knowledgeable about environmental issues. Among OECD partner countries, similar increases were observed in Indonesia, Qatar and Tunisia. Meanwhile, environmental awareness deteriorated the most, though only moderately, in Austria, the Czech Republic, Hong Kong (China), Italy, Japan and the Netherlands.

\section{But students are not becoming more optimistic about the environment.}

However, on average across OECD countries, the share of students who are optimistic about the fate of the planet - those who reported that the problems associated with environmental issues would get better over the next 20 years - remained relatively stable over the same period. In 2015, 15-year-olds were slightly more optimistic than their counterparts in 2006 about the problems associated with the clearing of forests, nuclear waste and air pollution, but more pessimistic about the availability of water in the future. 
Are environmentally aware students more pessimistic about the future of the earth? OECD average

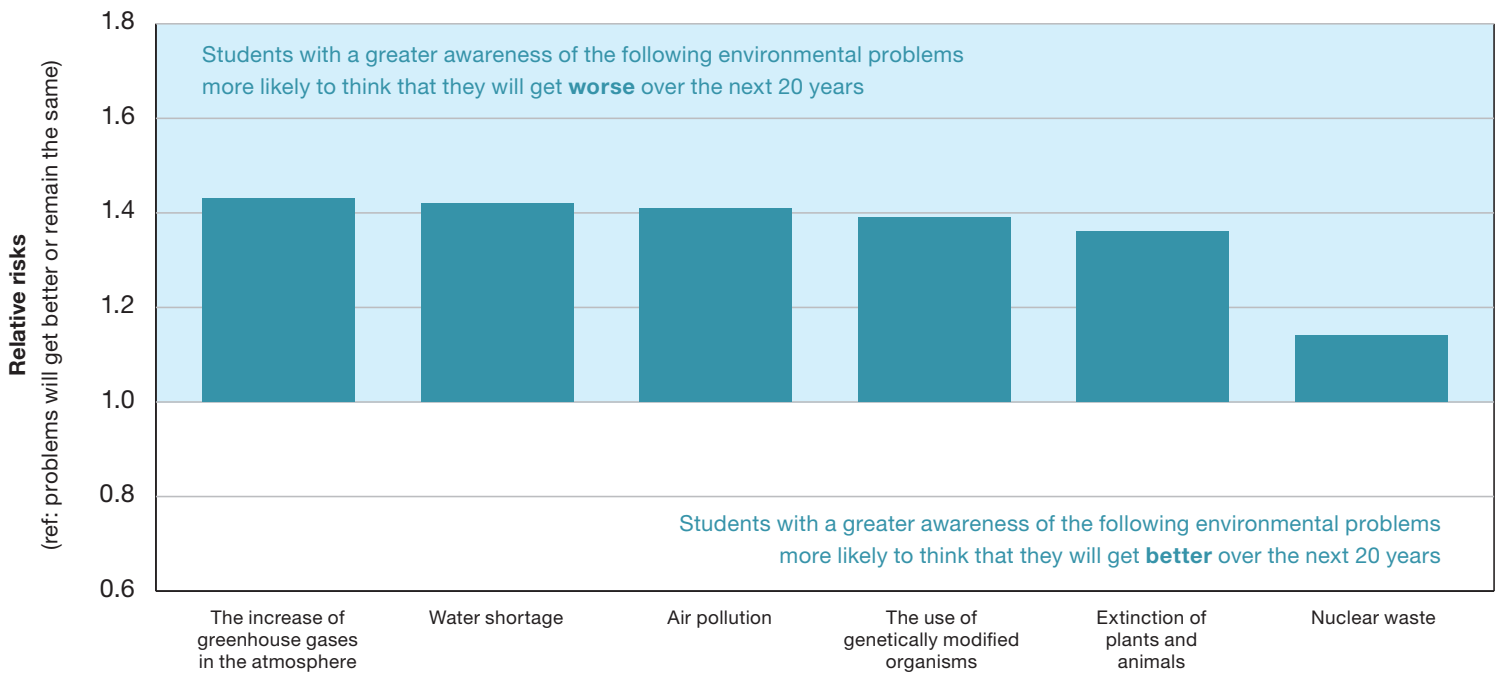

Students reported that they are knowledgeable about and can explain

the following environmental issues

1. Includes students who answered "I know something about this and could explain the general issue" or "I am familiar with this and I would be able to explain this well". The reference category includes students who answered "I have never heard of this" or "I have heard about this but I would not be able to explain what it is really about". Notes: Lithuania acceded to the OECD on 5 July 2018. The OECD average does not include Lithuania.

All values are statistically significant.

Source: OECD, PISA Database.

Optimism about environmental issues increased the most in Estonia, Japan and the Netherlands, but pessimism grew the most in Bulgaria, Chile, the Czech Republic, Hong Kong (China), Korea, Chinese Taipei and Turkey. Interestingly, in a majority of the school systems where environmental awareness improved between 2006 and 2015, such as Bulgaria, Chile, Iceland, Israel, Korea, Lithuania, Mexico, Sweden and Turkey, students' optimism about the future of the environment declined.

\section{Environmentally aware students are more pessimistic about the future of the earth.}

That a greater awareness does not lead to greater optimism is hardly surprising given that students who reported being knowledgeable about environmental issues were considerably more likely to consider that these problems would worsen in the future. For instance, 15 -year-old students who claimed to be informed about the increase of greenhouse gases, water shortages and air pollution were about $40 \%$ more likely to consider that these problems would get worse over the next 20 years.

\section{Many characteristics of students and schools are positively associated with environmental awareness, but only a few are also positively related to optimism about the environment.}

On average across OECD countries, students who reported greater awareness about the environment had many characteristics in common. For instance, socio-economically advantaged students were considerably more likely than disadvantaged students to say that they are knowledgeable about environmental problems. Scientifically-minded students - that is, high-performing students who participate in science activities, expect to pursue a career in science and are interested in broad science topics - showed greater environmental awareness. Students also tended to be environmentally aware when they reported greater exposure to enquiry-based teaching and, to a lesser extent, when the science department in their schools is well-resourced and offers science activities, including a science club and competitions. 
Who are the environmentally aware and optimistic students? Correlations at the student level, OECD average

Environmental optimism

Environmental awareness

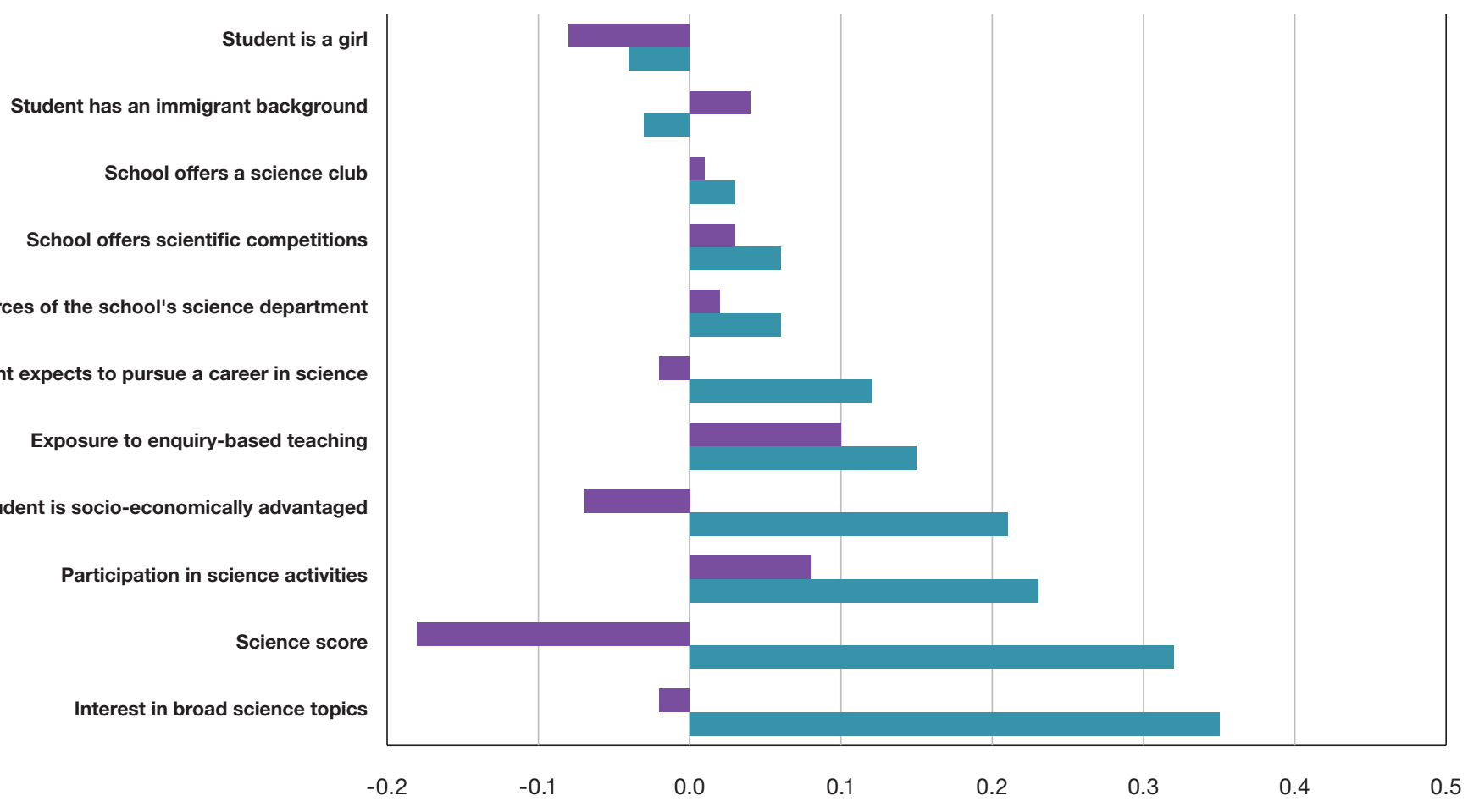

Notes: Lithuania acceded to the OECD on 5 July 2018. The OECD average does not include Lithuania.

All correlations coefficients are statistically significant.

Source: OECD, PISA Database.

Previous research has tried to determine what makes citizens adopt environmentally friendly behaviour - that is, actions that try to minimise the negative impact of humans on the environment. One of the findings emerging from this research is that environmental awareness is essential, but knowledge alone is not enough to promote action (see, for instance, the frequently cited work of Anja Kollmuss and Julian Agyeman). People who believe that these problems will get worse, for instance, may consider that whatever they do is insufficient or useless, though blind optimism might also be a recipe for inaction. So the question is: what can make students informed optimists? While PISA cannot prove cause and effect, only two factors showed a strong association with both awareness about environmental problems and a belief that these problems would be ameliorated over the next 20 years: the number of science activities in which students participate and students' exposure to enquiry-based teaching.

\section{The bottom line}

Most people agree that the environment has deteriorated over the past few decades, even if there is an ongoing debate about the magnitude and consequences of recent changes in the environment. Fortunately, there are plenty of public and private initiatives to protect the environment, and students around the globe are increasingly aware of the most important environmental problems affecting the planet today. However, students are not becoming more optimisitic about the earth's future. If we want to preserve the environment for future generations, it is essential that students increase their environmental awareness and use this knowledge to adopt sustainable lifestyles, lower the cost of action and search for innovative solutions to environmental problems. 


\section{For more information}

\section{Contact: Alfonso Echazarra (alfonso.echazarra@oecd.org)}

Coming next month: How are school success and school climate related to teachers' experience?

This paper is published under the responsibility of the Secretary-General of the OECD. The opinions expressed and the arguments employed herein do not necessarily reflect the official views of OECD member countries.

This document, as well as any data and map included herein, are without prejudice to the status of or sovereignty over any territory, to the delimitation of international frontiers and boundaries and to the name of any territory, city or area.

The statistical data for Israel are supplied by and under the responsibility of the relevant Israeli authorities. The use of such data by the OECD is without prejudice to the status of the Golan Heights, East Jerusalem and Israeli settlements in the West Bank under the terms of international law.

This work is available under the Creative Commons Attribution-NonCommercial-ShareAlike 3.0 IGO (CC BY-NC-SA 3.0 IGO). For specific information regarding the scope and terms of the licence as well as possible commercial use of this work or the use of PISA data please consult Terms and Conditions on www.oecd.org. 